\title{
An Interpretation of the 1914 Eruption of Sakurajima Volcano
}

\author{
By Izumi YoKoYama, M. J. A.
}

(Communicated April 14, 1997)

\begin{abstract}
The 1914 eruption of Sakurajima volcano, Japan was one of the largest volcanic eruptions in the history of this country. Hitherto, numerous papers have appeared discussing this eruption from various standpoints. Nevertheless, there still remain many data not fully analyzed from viewpoints of increased volcanological knowledge. In the present paper, its eruption processes are interpreted utilizing the observational data with relation to subsurface structure. Benchmark (BM) 2469 near the Kagoshima harbor proved to have upheaved approximately $12 \mathrm{~cm}$ relative to 1891 elevation before the 1914 eruption based on precise leveling surveys and the temporary sea level observations at the Kagoshima harbor. This was a part of the precursory upheaval around the volcano. BM. 2474 about $10 \mathrm{~km}$ northwest of the center of the volcano subsided approximately $80 \mathrm{~cm}$ by the eruption relative to the 1891 elevation, and $5 \mathrm{~cm}$ more during subsequent 7 months. Such subsidence was common to the other benchmarks around the volcano. This means that the subsidence was rheological: we may assume that a part of the subsidence was elastic and the rest was viscoelastic. Such movements can not be attributed to lava effusions that continued for only 1 month. Considering the sequences of the volcanic activity in connection with the subsurface structure of the volcano, one can surmise the magma movements: The lava flows began to effuse 36 hours after the first outburst of a column of white smoke from the summit crater. The first outburst may have been caused by contact of magma with the aquifer at a depth of $2.5 \mathrm{~km}$ below sea level based on analyses of the gravity anomalies there. If we adopt that the magma reached the first craterlet at $0.5 \mathrm{~km}$ above sea level after 36 hours, we may calculate magma ascent velocity of $2 \mathrm{~km} /$ day. Prior to the 1914 eruption, the first precursory shock of volcanic origin was observed 4 days prior to lava effusion. Thus, the starting point may be about $8 \mathrm{~km}$ below the sea level. This is the depth of a short lived pressure source which is interpreted as the cause of surface subsidence.
\end{abstract}

Key words : Sakurajima volcano; volcanogenic deformation; magma movement diagram; aquifer.

Introduction. Sakurajima volcano stands at the southern border of Aira caldera (Kagoshima Bay), southern Kyushu, Japan (Fig. 1). Repeated large eruptions have occurred during the historical periods. Its large eruptions are dated at $708,764,1476,1779$ before 1914 , and it erupted moderately in 1946. Since 1955, it has been erupting ashes from the summit crater of South Peak. The 1914 Sakurajima eruption was one of the largest ones in the 20th century of Japan. It overflowed a large amount of lavas, about $1.6 \mathrm{~km}^{3}$ which connected the volcanic island with Oosumi Peninsula. Many researchers have studied the eruption from various standpoints, e.g. Omori, ${ }^{1)}$ Koto, ${ }^{2)}$ and Yamaguchi. ${ }^{3)}$ Their papers contain some unsolved problems. Still it is important and interesting to reexamine the eruption on the basis of advanced knowledge.

Precursory activity of the 1914 eruption. The pre-eruption activity of the 1914 eruption was quantitatively observed by geodetic and seismometric methods.

Precursory deformation. Precise levels in this district were first conducted in 1891 and repeated in July-August 1914 (after the January 1914 eruption) and in February $1915,1919,1932,1946$, and thereafter, the survey has been repeated frequently. As for the deformation around the volcano immediately before the 1914 eruption, we have no exact data. At the time of the 1914 eruption, on Sakurajima volcano there were 10 triangulation points only, and no benchmarks for precise levels which were set up first in 1958 by Kyoto University.

Sea level observations at Kagoshima harbor. Selfrecording tide-gauge observation at the Kagoshima harbor began in 1915 after the eruption. We may refer some data of preparatory sea level observations at the Kagoshima harbor which were not continuous before the eruption. The first systematic determinations of the sea level there 


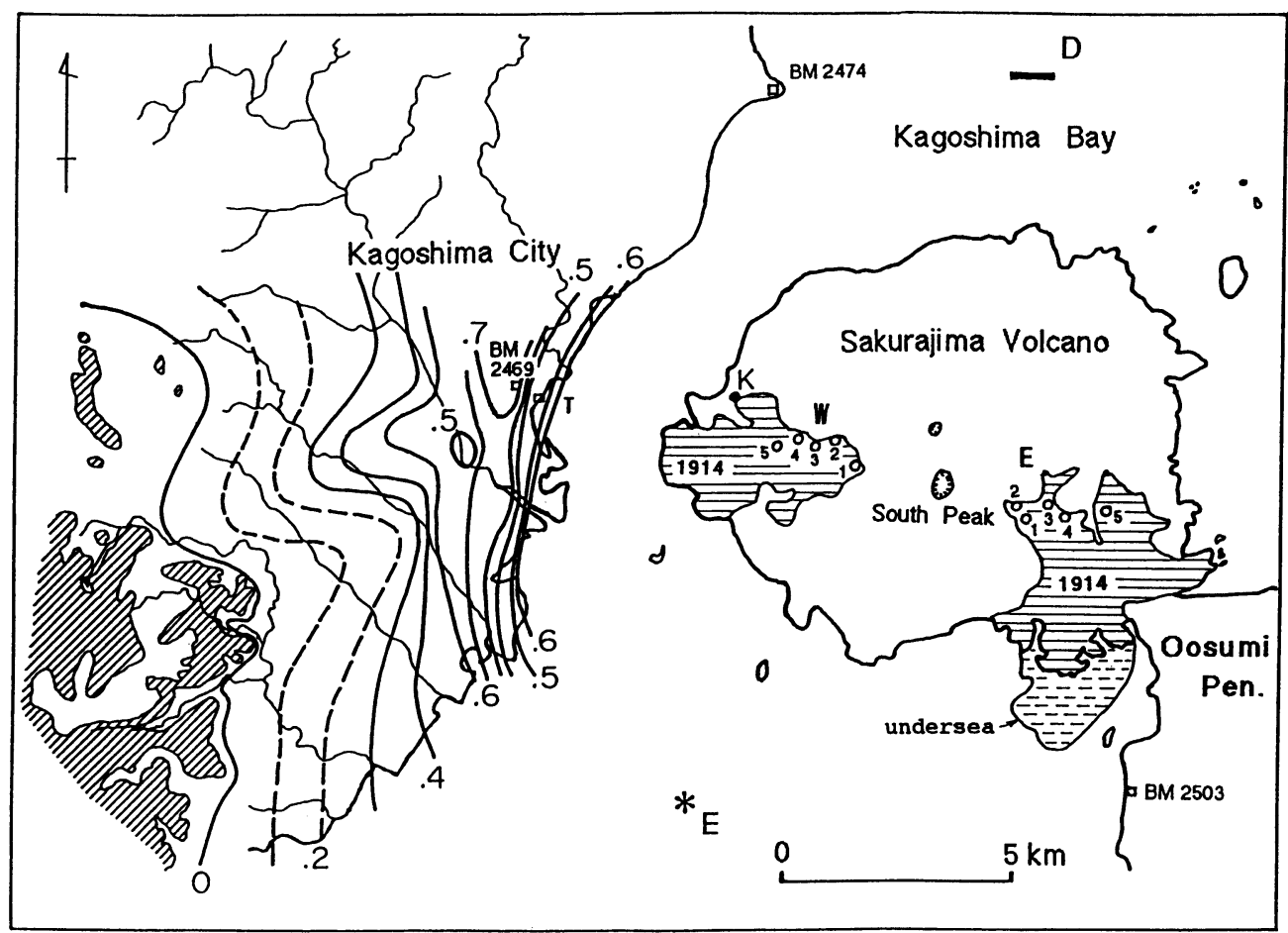

Fig. 1. Sakurajima volcano and the surrounding area. T: Tide-gauge station, D: Approximate center of the depression caused by the 1914 eruption, E: Approximate epicenter of the earthquake M 7.1 (after Abe ${ }^{4)}$ ). Hollow circles on the volcano show the craterlets, and contours show the depths of the basement in kilometers and hatched parts indicate basement outcrops (after Hayasaka and $\mathrm{Oki}^{7}$ ).

were made for the period of January 1903 to April 1905 and for a month from May to June 1909 by means of a graduated tide-gauge rod erected at the harbor office quay which was connected to BM. 2469 (Fig. 1) by precise levels. The data were examined and discussed by $\mathrm{Omori}^{1)}$ : Changes in sea level relative to 1904 are summarized as follows:

May-June 1909: $+5.7 \mathrm{~cm}$,

Jan. 1914 immediately before the eruption: unknown,

Feb.-Mar. 1914 after the eruption: $+42 \mathrm{~cm}$.

Thus, BM. 2469 had subsided $42 \mathrm{~cm}$ by Feb. 1914 relative to 1904. On the other hand, the precise levels made in July-August 1914 found a subsidence of BM. 2469 as $-40.7 \mathrm{~cm}$ relative to 1891 and to the tide-gauge station located at a distance of approximately $140 \mathrm{~km}$, i.e. we can say that BM. 2469 had kept roughly the same height since 1891 to 1904 considering the accuracy of the sea level determinations and that it upheaved about $6 \mathrm{~cm}$ from 1904 to 1909. Then, we may estimate the upheaval of BM. 2469 immediately before the 1914 eruption as $12 \mathrm{~cm}$ by linear extrapolation. Consequently BM. 2469 subsided about (12 $+40.7)=\mathrm{ca} .53 \mathrm{~cm}$ in total, associated with the eruption. In general, such precursory upheavals are rather common in the areas of active volcanoes.

Similarly, BM. 2474 which subsided most among the benchmarks around the volcano, should have upheaved before the eruption, probably more than $20 \mathrm{~cm}$ because its subsidence by the 1914 eruption was roughly twice that of BM. 2469. The subsidence of BM. 2474 observed after the 1914 eruption was $63 \mathrm{~cm}$ relative to 1891 and to BM. 2503 at the Oosumi Peninsula (Fig. 1). Thus we may assume the total subsidence of BM. 2474 accompanying the 1914 eruption of roughly $85 \mathrm{~cm}$.

Precursory seismic activity. The Gray-Milne seismograph observation was made after Jan. 11, 1914 at the Kagoshima meteorological observatory located at a distance of about $10 \mathrm{~km}$ from the eruption center. The recording drum of the seismographs was triggered into motion by intense shocks over a certain threshold, and the point magnifications were 5 to 10 . At Nagasaki, about 148 $\mathrm{km}$ north of the volcano, the Omori horizontal pendulum tromometers registered the Sakurajima earthquakes. The magnifications of the two components were 20 and 120 .

Prior to the outburst of the Sakurajima eruption, in May and June 1913, earthquake swarms occurred in the Yoshimatsu area at the NW foot of Kirishima volcano, 55 $\mathrm{km}$ to the north of Kagoshima City, and on Nov. 8, Dec. 9, 


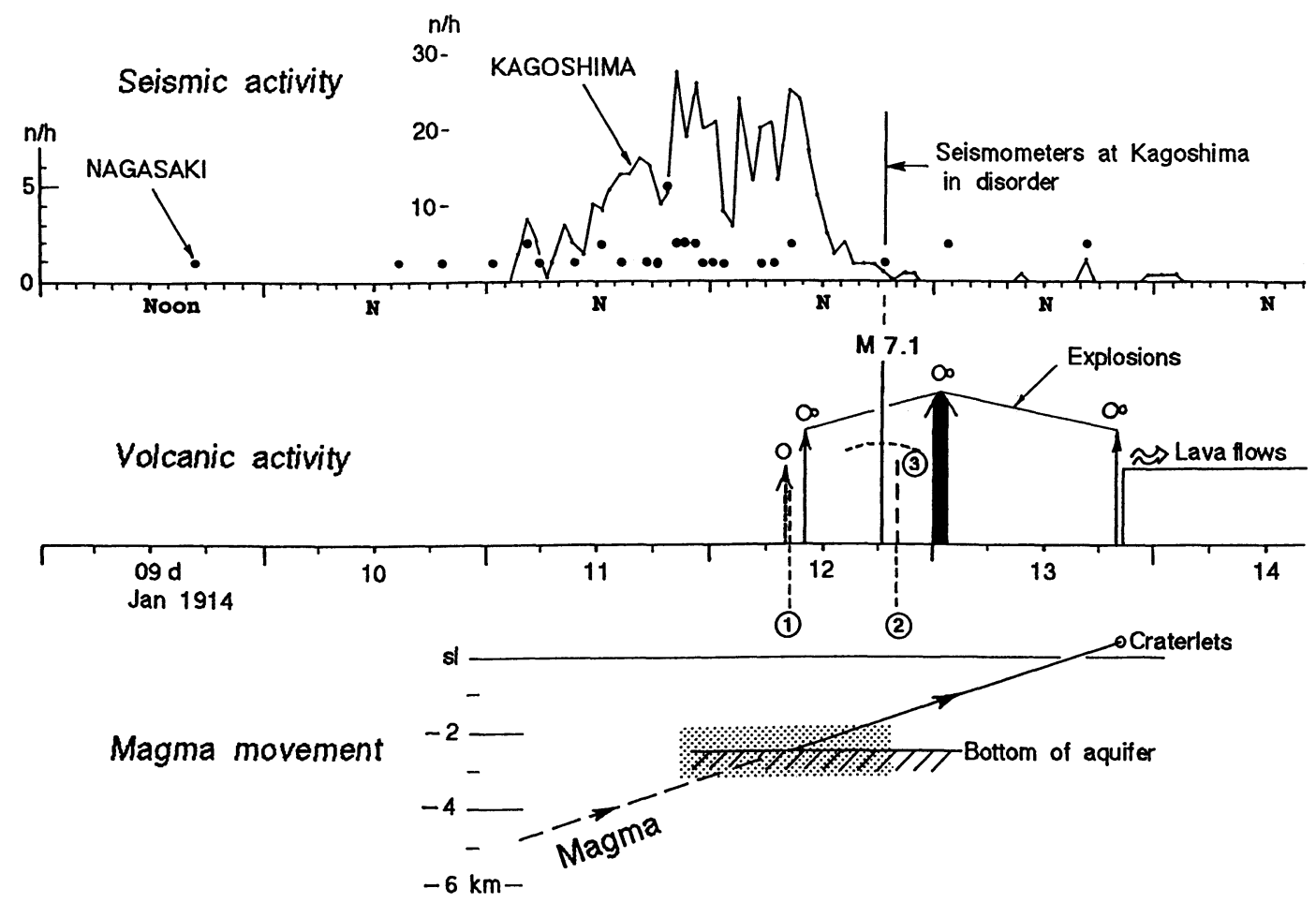

Fig. 2. Sequence of the 1914 eruption of Sakurajima volcano.

Seismic activity Hourly number of the Sakurajima earthquakes observed at Nagasaki and Kagoshima.

Volcanic activity 0 : Eruption in the central crater, $\infty$ : Eruption in parasitic craters, $\approx$ : Lava flow, $\hat{i}:$

Phreatic explosion. Thick arrow shows the most violent stage of parasitic explosions.

(1): Water gushing at the shore of the island,

(2): Small tsunami observed at the Kagoshima harbor,

(3): Probable time range of submarine cable breakdown.

Magma movement Dotted area shows approximate position of contacts between magma and water.

1913 and on Jan. 8, 1914, Kirishima volcano successively went into small explosions ejecting ashes. These activities indicate a tectonically activated stage of the region including Sakurajima volcano, but may have no direct relationship to the 1914 eruption of Sakurajima volcano.

Occurrences of volcanic earthquakes observed by the Kagoshima and Nagasaki seismographs are shown in Fig. 2. In fact, from the morning of Jan. 10, many shocks were felt in Kagoshima City. The earthquake swarm was active before the vents opened on both the eastern and western slopes of the volcano, and rapidly decreased after explosions began at the vents. The earthquakes were caused by stress accumulation before the vents opened.

Sequences of the 1914 eruption. Sequences of volcanic activity of Sakurajima volcano in the early stage (Jan. 9 to 14) in the 1914 eruption are briefly described as follows and schematically represented in Fig. 2:

[Jan. 9 afternoon, 1914] Volcanic earthquakes began according to the seismometrical observation at Nagasaki.

[Early morning of Jan. 12] At the southern shore of the island, hot water began to be issued copiously and water bubbled up among the sea and the hot spring was thrown up in jets to a height of about 1 meter (1) in Fig. 2). Simultaneously, at the northern shore, the discharge of natural cold springs was considerably augmented.

[0800 h Jan. 12] A column of white smoke was suddenly shot up in the form of a pine tree from the top of South Peak.

[1000 h] Explosions began at the western slope and $10 \mathrm{~min}$ later at the eastern slope. After the openings of the vents, earthquake activity rapidly decreased.

[1830 h] The largest earthquake M 7.1 occurred.

[2030 $\mathrm{h}$ approx.] Small tsunami was observed (2) in Fig. 2), being not directly related to the large earthquake: Omori ${ }^{1)}$ reports as follows: "The waters in the harbor of Kagoshima, whose level was then only about 1.5 feet below the top surface of the quay wall, flowed a little over the latter and partially washed the strand streets, a few boats there being damaged. The cause of the small tsunami was probably in a small sudden settlement or depression of 
the bay bottom."

[2000 h approx.] Submarine cables between Kagoshima and Sakurajima Island were cut down halfway probably sometime between $14 \mathrm{~h}$, Jan. 14 and the next morning (3) in Fig. 2).

[0100 h approx. Jan. 13] Explosions were strongest.

[2000 $\mathrm{h}$ approx.] Lava began to effuse from craterlets on both the western and eastern sides: on the western side, the highest craterlet was located at about $550 \mathrm{~m}$ above sea level (asl) and $0.33 \mathrm{~km}^{3}$ of lava was effused. On the eastern side, the highest craterlet was located at $380 \mathrm{~m}$ asl and the effused lava flows were $1.23 \mathrm{~km}^{3}$. Total volume of the lavas amounted to $1.6 \mathrm{~km}^{3}\left(\mathrm{Omori}^{\mathrm{i}}\right)$.

[Early February 1914] The main lava flows stopped on both sides, but a small lava flow on the eastern side began to effuse in mid-February and was slow but continued for approximately 1 year (Yamaguchi ${ }^{3)}$ ). The volume of the early lava flow was much larger than the latter.

Volcanic earthquakes. The precursory earthquakes of the eruption were first recorded by the Nagasaki seismographs in the afternoon of Jan. 9 when the Kagoshima seismographs did not work (Fig. 2). During the period from Jan. 11 to the morning of Jan. 12, 11 earthquakes of magnitudes ranging between 4.8 and 5.2 swarmed, and their cumulative seismic energy amounted to $10^{20} \mathrm{erg}$ in order of magnitude. The swarm activity was much reduced at or just prior to the opening of the eruption in the morning of Jan. 12. This indicates that stress accumulation at shallow depths had been partly released by openings of the vents on the slopes. In the evening of Jan. 12 , the largest earthquake of M 7.1 (ca. $10^{22} \mathrm{erg}$ ) occurred. It is extraordinarily large for those of volcanic origin and caused disorder of the seismometers at Kagoshima. Its epicenter is shown in Fig. 1 and its depth is about $8 \mathrm{~km}$ according to Abe. ${ }^{4)}$ It occurred probably to readjust the stress in the crust caused by magma intrusions. The effused magma amounted to $1.4 \mathrm{~km}^{3}$ in dense rock equivalent. The volume of the original magma at the depths should be much larger, perhaps 10 times this volume.

Volcanogenic subsidences. The leveling routes in this district were set up in 1891 . The 2 nd survey was made in July to August after the explosions calmed in June 1914, and BM. 2474 about $10 \mathrm{~km}$ northwest of the center of the volcano (Fig. 1) was found to have subsided about $63 \mathrm{~cm}$ during the interval relative to BM. 2503. In fact, it should have upheaved more than $20 \mathrm{~cm}$ immediately before the eruption as mentioned above, and the total subsidence should be around $85 \mathrm{~cm}$. The 3rd survey in February 1915 found that the benchmark subsided about $5 \mathrm{~cm}$ more. The next survey in 1919 revealed a recovery of about $12 \mathrm{~cm}$

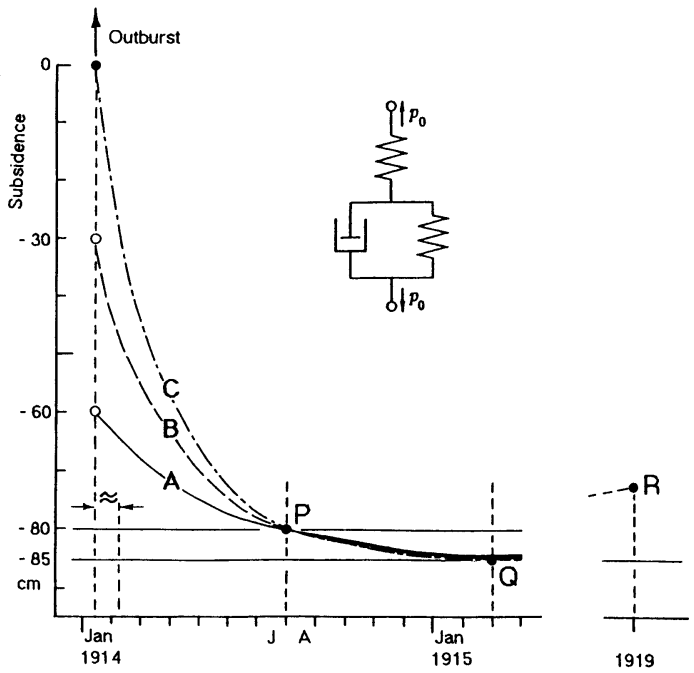

Fig. 3. Assumptive subsidence of BM. 2474 associated with the 1914 eruption of Sakurajima volcano. Curves A, B and C: See the text. Solid circles indicate the observations. A wavy mark around January 1914 shows the lava effusion.

since 1915. Such behavior was confirmed at all the benchmarks around the volcano. From these facts, we assume that a part of the subsidence occurred quasisimultaneously with the January 1914 eruption, and the rest had gradually progressed by February 1915. The 1915 level may have been the lowest followed by recovery. The recovery stage is interpreted as a rheological behavior of the crust by the present author (Yokoyama ${ }^{5)}$ ).

A problem is at what stage and how the subsidence took place. Considering that there were no reports about rapid subsidence around the volcano after the eruption, we may suppose that the majority of the subsidence occurred elastically soon after the violent explosions centering at $0100 \mathrm{~h}$ Jan. 13. Here, BM. 2474 is adopted as a typical example of the subsidences at the periphery of Kagoshima Bay. Assuming that the additive subsidence of $5 \mathrm{~cm}$ after July 1914 is a part of elastic aftereffect, we may figure possible exponential subsidence curves passing point $\mathrm{P}$ as shown in Fig. 3: The following three models of instantaneous elastic subsidence are illustrated in the figure.

A) Elastic subsidence $50 \mathrm{~cm}$ and then viscoelastically $35 \mathrm{~cm}$,

B) Elastic subsidence $30 \mathrm{~cm}$ and then viscoelastically $55 \mathrm{~cm}$,

C) Totally viscoelastic subsidence $85 \mathrm{~cm}$.

The values calculated for the above models are quasiidentical at Feb. 1915 (point Q in Fig. 3), within the error of the precise levels. We can not discriminate the best fitting of the three models. Lava effusions continued for less than 1 month and stopped in early February (Fig. 3). 


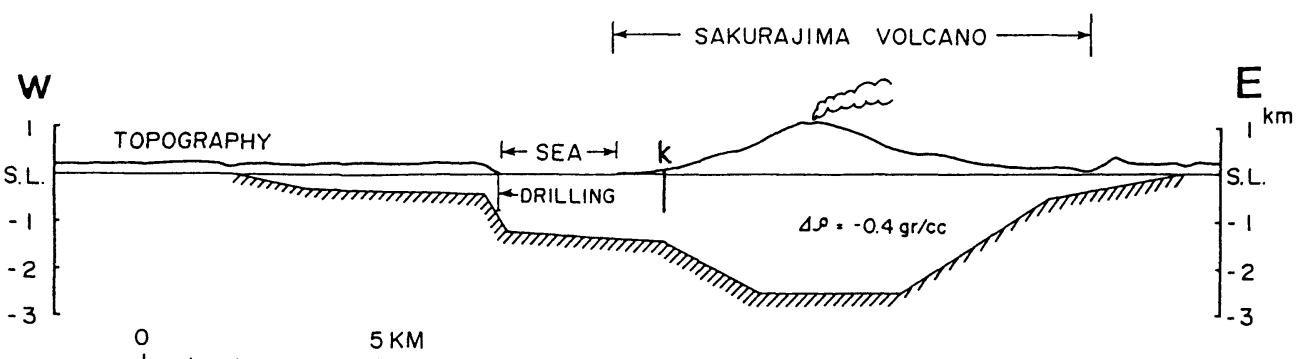

Fig. 4. A schematic profile connecting Kagoshima and Sakurajima volcano deduced mainly from gravity anomalies (Yokoyama and $\left(\mathrm{Ohkawa}^{6}{ }^{6}\right)$. K: Drilling at Koike ( $800 \mathrm{~m}$ deep). Hatched lines indicate the top of the basement.

This suggests no direct relationship between subsidence and lava effusions. In other words, the subsidence was not caused by removal of magma from the reservoir, but by pressure release. Curve " $\mathrm{C}$ " has a higher rate of subsidence than the others, and is not reasonable in this case. We should prefer model "A" or similar one. In summary, the majority of a large subsidence amounting to approximately $85 \mathrm{~cm}$, subsided elastically and the remainder viscoelastically.

Scenario of the 1914 eruption. Knowledge of the subsurface structure beneath volcanoes is indispensable to discuss mechanisms of their activity.

Subsurface structure of Sakurajima volcano. At present we have insufficient knowledge about the subsurface structure beneath Sakurajima volcano. Yokoyama and Ohkawa ${ }^{6)}$ discussed the subsurface structure of Aira caldera and its vicinity by analyzing gravity, geomagnetism, and explosion seismology data. A schematic profile in E-W direction is shown in Fig. 4. On the other hand, Hayasaka and $\mathrm{Oki}^{7)}$ obtained the depth contours of the basement rocks beneath Kagoshima City using drilling data as shown in Fig. 1 where the basements are the lower Tertiary (Shimanto layer). At Koike near the western coast of the volcano island, one well was bored. It reaches a depth of $800 \mathrm{~m}$ below sea level (bsl), and does not reach the basement. The cores contain many layers of tuff and pumice. Here the layers overlying the basement may be aquifers.

Magma movement diagram. Considering the early part of the sequences presented in Fig. 2 and the structural profile shown in Fig. 4, we may surmise that the magma contacted with the aquifers beneath Sakurajima volcano around $1000 \mathrm{~h}$, Jan. 12 provoking a column of smoke to be issued at the summit crater and hot water to be ejected at the sea shore. The bottom of the aquifers is about $2.5 \mathrm{~km}$ bsl corresponding to the basement depth. The approximate time range of magma-water contact is around Jan. 12 as shown by the dotted area at the bottom of Fig. 2 which is a "magma movement diagram". It suggests the possible magma movements with time. Lava appeared first at the vent at about $500 \mathrm{~m}$ asl. If we assume uniform upward movement of the magma, it may have moved as shown in Fig. 2. Then, an apparent velocity of the upward movement of the magma is estimated as $3.0 \mathrm{~km} / 36 \mathrm{hr}=$ $2.0 \mathrm{~km} /$ day.

The first precursory earthquake was observed at Nagasaki on Jan. 9 when the Kagoshima seismometers did not work. The hypocenter of this earthquake may have been roughly equal to the starting point of the magma. If we assume that the magma path was vertical and the ascent velocity was uniform, the starting depth of the magma is estimated approximately at $2 \mathrm{~km} /$ day $\times 4$ days $=$ $8 \mathrm{~km}$. This depth agrees with that of the oblique pressure source beneath Sakurajima volcano interpreted as the cause of surface deformation of the ground around both the volcano and the caldera during the 1914 eruptions $\left(\right.$ Yokoyama ${ }^{8)}$ ).

It is noticeable that all the historical lava eruptions of this volcano occurred halfway down the slopes of the volcano and not from the summit craters at a level of 1100 $\mathrm{m}$ asl. In the large eruptions of the 15th century, the lavas issued from the craterlets of 200 to $400 \mathrm{~m}$ in elevation, and in the large eruptions of the 18th century, from those of 650 to $850 \mathrm{~m}$. And in 1946, the volcano effused lava flows from a craterlet at an elevation of $800 \mathrm{~m}$ on the slope of South Peak. After 1955, the volcano has been issuing volcanic ashes from the summit crater of South Peak.

During the 1914 eruption, the eruptions on both the eastern and western slopes burst quasi-simultaneously and their vents were at very similar elevation and duration of their activity were also similar. The lava volume on the eastern slope is about $1.2 \mathrm{~km}^{3}$ and that on the western slope is about $0.3 \mathrm{~km}^{3}$. Such simultaneous effusion of lavas from the vents on both sides of the volcano leads to a 
model of bilateral parasitic injection of magmas $\left(\operatorname{Koto}^{2)}\right)$. The crossroads of the magma vents should be a little shallower than $2.5 \mathrm{~km}$ and the highest eruptive activity at the midnight of Jan. 12-13 may have been caused by fullscale contacts of magma and main aquifer. Its depth is about $1 \mathrm{~km}$ bsl as shown in the magma movement diagram (Fig. 2).

Concluding remarks. The magma movement diagram of the 1914 Sakurajima eruption is constructed by considering the sequence of the eruption in connection with the subsurface structure of the volcano. It shows that apparent upward velocity of the magma is approximately 2 $\mathrm{km} /$ day. The first volcanic earthquake occurred 4 days prior to the magma effusion: Then the magma was at a depth of about $8 \mathrm{~km}$ bsl. The crossroads of the magma vents for the bilateral parasitic injection prove to have been about $2 \mathrm{~km}$ bsl, and the highest explosive activity appears to have occurred when the magma was at a depth of about $1 \mathrm{~km}$ bsl. Majority of the subsidence caused by the eruption should be elastic and the rest should be viscoelastic. It is clear that magma effusion is not directly related to the subsidence because the former continued for a month and the latter for more than one year.

To improve our knowledge about magma movements, we need more concrete information on the subsurface structure beneath the volcano and also more and deeper drillings. We should find any common factors between the 1914 magmatic eruptions and the ash eruptions currently in progress.

Acknowledgements. The author is heartfully grateful to Dr. Charles W. Mandeville, Geological Survey of Japan, for critically reviewing the early version of the manuscript.

\section{References}

1) Omori, F. (1914-1922) Bull. Imp. Earthq. Invest. Comm. 8, $1-525$.

2) Koto, B. (1916) J. College Sci., Imp. Univ. Tokyo 38, 1-237.

3) Yamaguchi, K. (1975) Japan Earth Sciences Education Society. Tokyo, pp. 1-128 (in Japanese).

4) Abe, K. (1979) J. Fac. Sci., Hokkaido Univ., ser. VII 6 , 202-212.

5) Yokoyama, I. (1996) Proc. Japan Acad. 72B, 124-128.

6) Yokoyama, I., and Ohkawa, S. (1986) J. Volcanol. Geotherm. Res. 30, 253-282.

7) Hayasaka, S., and Oki, K. (1971) J. Fac. Sci., Kagoshima Univ., Geol. Biol. 4, 15-29 (in Japanese).

8) Yokoyama, I. (1986) J. Volcanol. Geotherm. Res. 30, 283-302. 